\title{
Hospital electronic prescribing system implementation impact on discharge information communication and prescribing errors: a before and after study
}

\author{
Pamela Ruth Mills ${ }^{1,2}$ (D) Anita Elaine Weidmann ${ }^{2} \cdot$ Derek Stewart $^{2}$
}

Received: 3 February 2017 / Accepted: 25 May 2017 /Published online: 22 June 2017

(C) The Author(s) 2017. This article is an open access publication

\begin{abstract}
Purpose The study aimed to test the hypothesis that hospital electronic prescribing and medicine administration system (HEPMA) implementation impacted patient discharge letter quality, nature and frequency of prescribing errors.

Method A quasi experimental before and after retrospective case note review was conducted in one United Kingdom district general hospital. The total sample size was 318 (random samples of 159 before and after implementation), calculated to achieve a $10 \%$ error reduction with a power of $80 \%$ and $p<0.05$. Adult patients discharged after $\geq 24$-h inpatient stay were assessed for discharge information documentation quality using a modified validated discharge document template. Prescribing errors were classified as medicine omissions, commissions, incorrect dose/frequency/duration, drug interactions, therapeutic duplications or missing/inaccurate allergy information. Post-implementation assessments were undertaken 4 months following HEPMA implementation. Error severity was determined by a multidisciplinary panel consensus using the Medications at Transitions and Clinical Handoffs (MATCH) study validated scoring system.

Results There were no statistically significant differences in patient demographics between the pre- and postimplementation groups. Discharge information documentation quality improved; allergy documentation increased from 11 to $159 / 159(p<0.0001)$. The number of patients with
\end{abstract}

Pamela Ruth Mills

pamela.mills@aaaht.scot.nhs.uk

1 University Hospital Crosshouse, Pharmacy Department, Kilmarnock, Ayrshire KA2 OBE, Scotland, UK

2 School of Pharmacy and Life Sciences, Robert Gordon University, Aberdeen AB10 7GJ, Scotland, UK prescribing errors reduced significantly from 158 to $37 / 159$ $(p<0.001)$. Prescribing error category incidence identified in pre-implementation patients was reduced (e.g. omission incidence from 66 to $18 / 159(p<0.001)$ ), although a new error type (sociotechnical [errors caused by the system]) was identified post-implementation ( $n=8$ patients). Postimplementation prescribing errors severity rating identified $8 / 37$ as likely to cause potential patient harm.

Conclusion HEPMA implementation was associated with improved discharge documentation quality, statistically significant prescribing error reduction and prescribing error type alteration. There remains a need to be alert for potential prescribing errors.

Keywords HEPMA · Prescribing error $\cdot$ Sociotechnical error

\section{Introduction}

Hospital electronic prescribing and medicines administration (HEPMA) systems were defined by the Department for Health in England in 2007 as 'the utilisation of electronic systems to facilitate and enhance the communication of a prescription or medicine order, aiding the choice, administration and supply of a medicine through knowledge and decision support and providing a robust audit trail for the entire medicines use process' [1]. UK government strategy recommends HEPMA system implementation, with National Health Service (NHS) England and NHS Scotland policies committed to HEPMA as a future ehealth model in all secondary healthcare settings $[2,3]$.

Reported advantages of electronic prescribing systems include increased patient safety by prescribing error reduction. The UK Health Foundation stated that implementation of an electronic prescribing system incorporating decision support functionality could realise a $50 \%$ prescribing error reduction 
[4]. These systems also have the capacity to create prescriptions at the point of patient discharge from secondary care [5]. Electronic systems are, not without their limitations, having been shown to lead to 'sociotechnical errors', defined as those 'occurring at the point where the system and the professional intersected and would not have occurred in the absence of the system' [6].

In the UK, implementation of electronic prescribing systems is variable. A survey of English hospitals in 2011 reported that while $48 \%$ of hospitals had implemented standalone electronic discharge systems, only $13 \%$ had implemented integrated inpatient and discharge electronic prescribing [7]. Reduction in inpatient prescribing errors has been demonstrated with electronic prescribing systems [8, 9]. However, there has been limited study of prescribing error alteration in discharge prescriptions. A narrative literature review of discharge information communication and medicines discharge prescribing errors identified four studies comparing electronic solutions to traditional handwritten systems and five of electronic solutions with no comparison. These studies demonstrated inconsistent results with improved, unchanged or reduced medicine information accuracy [10]. Notably, none of the study sites had implemented the UK HEPMA systems.

Healthcare Improvement Scotland state that HEPMA systems need to be at least as safe as the traditional paper systems they replace [11]. Guidance on hospital medicines discharge documentation requirements are provided by two UK bodies, the Royal Pharmaceutical Society (RPS) and the Scottish Intercollegiate Guideline Network (SIGN) $[12,13]$. The RPS guidance proposes core content for medicines information communication on hospital discharge, including a mandatory requirement for medicines change information to be recorded [12]. SIGN guidance defines the ideal content of hospital discharge documentation including a standard template with 29 required sections [13]. In 2014, NHS England identified specific issues concerning discharge medicines information communication which resulted in widespread dissemination of a patient safety alert to highlight the importance of essential information communication on discharge [14]. Medicine-related events are the most common adverse event occurring following hospital discharge, with evidence of perpetuation of discharge prescribing errors associated with a moderate potential for harm [15]. Failure to recognise these adverse events is a contributory factor for hospital readmission [16].

Currently, there is a lack of published evidence relating to HEPMA impact on discharge medicines information communication and prescribing error prevalence.

The aim of this study was to test the hypothesis that HEPMA implementation impacted discharge letter quality, nature and frequency of prescribing errors.

\section{Methods}

\section{Design}

A quasi experimental, before and after retrospective case note review design was adopted.

\section{Setting}

The study was undertaken in a 560 bedded district general hospital (DGH) in the UK. The selected HEPMA system was a commercially available standalone system; HEPMA implementation commenced in October 2013 and was completed in September 2014. Prior to HEPMA implementation, manual handwritten immediate discharge letters (IDLs) were prepared by either a medical prescriber or an advanced nurse practitioner transcribing diagnostic information from handwritten case notes and inpatient chart(s). Post-HEPMA implementation, both the inpatient prescription chart and the IDL were prepared electronically while the case notes remained handwritten. The IDL is prepopulated with information such as demographics and allergies. Discharge medicines can be selected from those prescribed as an inpatient and those to be commenced at the point of discharge added. Diagnostic and other clinical information is added by the clinician completing the IDL.

\section{Sampling}

The sample size calculation was based on anticipated baseline error rate of $17.5 \%$ [10]. The aim was to achieve a $10 \%$ error reduction with a power of $80 \%$ and $p<0.05$. The total sample size was 318 , comprising random samples of 159 before and after implementation.

Patient inclusion criteria were as follows:

- Discharged between April to June 2013 (pre) and February to April 2015 (post)

- $\geq 16$ years

- Discharged from hospital after an inpatient stay of at least $24 \mathrm{~h}$

Patient exclusion criteria were as follows:

- Mental health, maternity and paediatric wards (HEPMA not implemented or implemented prior to the study)

- No medicines prescribed at discharge

- Inter-hospital transfer 


\section{Pre-implementation data collection}

Case notes were reviewed retrospectively by the principal investigator, an experienced clinical pharmacist, with a focus on information content and presence of prescribing errors on the handwritten IDL by scrutinising clinical notes, inpatient prescription charts and IDLs. Data were extracted onto a data collection tool, which was a modified version of the SIGN discharge document template [13]. Variables documented were age, gender, general practitioner details, hospital consultant details, discharge ward, discharge specialty, length of stay, discharge day of week, primary diagnosis, secondary diagnosis, significant operations/procedures, allergies, number of medicines prescribed on IDL, and designation of clinician completing and IDL. An independent clinical pharmacist confirmed the reliability of data extraction in a random sample of $10 \%$ of patients.

Data of primary diagnosis, secondary diagnosis and significant operations/procedures were not assessed for accuracy, merely recorded as present or absent in accordance with the approach of Callen et al. [17].

Medicines prescribed on discharge were compared to the inpatient list to identify any discrepancies.

The definition of prescribing error of Dean et al. was adopted, 'a prescribing error occurs, when as a result of a prescribing decision or prescription writing process, there is an unintentional reduction in the probability of treatment being timely and effective or increase in the risk of harm' [18]. Prescribing error types were classified as medicine omission, medicine commission, incorrect dose, incorrect frequency, incorrect duration, drug interaction, therapeutic duplication, missing allergy and inaccurate allergy, as described in Table 1. Reliability of error categorisation in a random sample of $10 \%$ was confirmed by an independent clinical pharmacist.

\section{Post-implementation data collection}

A similar method was adopted for the post-implementation phase. Prescribing errors were identified and categorised as before, with the addition of sociotechnical errors in the postimplementation group. Examples of sociotechnical errors include incorrect selection of medicine formulation $[6,19]$. Following data extraction, one medical consultant and one clinical pharmacist scored prescribing error severity. The panel was provided with information about each prescribing error as per previous studies [20]. The panel were also provided with a copy of the severity scoring guidance which consisted of a validated scoring system developed by Gleason et al. [21]. The severity ratings were as follows:

1. No potential harm

2. Monitoring or intervention potentially required to preclude harm
Table 1 Error type classification

\begin{tabular}{|c|c|c|}
\hline Error type & Description & Exclusion \\
\hline Omission & $\begin{array}{l}\text { Medicine omitted from } \\
\text { IDL currently } \\
\text { prescribed on inpatient } \\
\text { chart. Medicine } \\
\text { administered } \\
\text { preceding/discharge } \\
\text { day. For example } \\
\text { documentation of 'no } \\
\text { changes to routine } \\
\text { medicines'. }\end{array}$ & $\begin{array}{l}\text { Medicine not usually } \\
\text { required on discharge, } \\
\text { for example antiemetic } \\
\text { injection. }\end{array}$ \\
\hline Commission & $\begin{array}{l}\text { Medicine prescribed on } \\
\text { IDL not on } \\
\text { pre-admission list. } \\
\text { Medicine not } \\
\text { administered } \\
\text { preceding/discharge } \\
\text { day, e.g. cyclizine } \\
\text { (antiemetic) prescribed } \\
\text { as a precaution but } \\
\text { never administered. }\end{array}$ & $\begin{array}{l}\text { Explanatory note } \\
\text { documented for } \\
\text { medicine requirement. }\end{array}$ \\
\hline Incorrect dose & $\begin{array}{l}\text { Discrepancy between dose } \\
\text { on inpatient chart and } \\
\text { IDL or no dose } \\
\text { documented, e.g. } \\
\text { carvedilol noted as } \\
19 \mathrm{mg} \text { instead of } \\
18.75 \mathrm{mg}\end{array}$ & $\begin{array}{l}\text { Explanatory note } \\
\text { documented regarding } \\
\text { dose change. }\end{array}$ \\
\hline $\begin{array}{l}\text { Incorrect } \\
\text { frequency }\end{array}$ & $\begin{array}{l}\text { Discrepancy between } \\
\text { frequency documented } \\
\text { on inpatient chart and } \\
\text { IDL or none } \\
\text { documented. For } \\
\text { example, as required } \\
\text { medicines prescribed } \\
\text { without specified time } \\
\text { interval. }\end{array}$ & $\begin{array}{l}\text { Explanatory note } \\
\text { documented regarding } \\
\text { frequency change. }\end{array}$ \\
\hline $\begin{array}{l}\text { Incorrect } \\
\text { duration }\end{array}$ & $\begin{array}{l}\text { Discrepancy between } \\
\text { duration documented on } \\
\text { inpatient chart and IDL } \\
\text { or no documented } \\
\text { duration provided. }\end{array}$ & $\begin{array}{l}\text { Explanatory note } \\
\text { documented regarding } \\
\text { duration change. }\end{array}$ \\
\hline $\begin{array}{l}\text { Drug } \\
\quad \text { interaction }\end{array}$ & $\begin{array}{l}\text { A drug interaction } \\
\text { recorded as a serious } \\
\text { interaction in current } \\
\text { edition of British } \\
\text { National Formulary. }\end{array}$ & $\begin{array}{l}\text { Appropriate to } \\
\text { co-prescribe with suit- } \\
\text { able monitoring. }\end{array}$ \\
\hline $\begin{array}{l}\text { Therapeutic } \\
\text { duplication }\end{array}$ & $\begin{array}{l}\text { More than one medicine } \\
\text { prescribed from same } \\
\text { therapeutic group. } \\
\text { Co-codamol and } \\
\text { tramadol co-prescribed. }\end{array}$ & $\begin{array}{l}\text { Protocol exists to evidence } \\
\text { prescribing action. }\end{array}$ \\
\hline Missing allergy & $\begin{array}{l}\text { Allergy documented on } \\
\text { inpatient chart and/or } \\
\text { patients' case notes but } \\
\text { not on IDL. Nil known } \\
\text { drug allergy (NKDA) } \\
\text { missing from IDL. }\end{array}$ & $\begin{array}{l}\text { Explanatory note } \\
\text { documented regarding } \\
\text { allergy information. }\end{array}$ \\
\hline $\begin{array}{c}\text { Inaccurate } \\
\text { allergy }\end{array}$ & $\begin{array}{l}\text { Discrepancy between } \\
\text { allergy documented on } \\
\text { inpatient chart and/or } \\
\text { patients' case notes and } \\
\text { IDL. }\end{array}$ & $\begin{array}{l}\text { Explanatory note } \\
\text { documented in case } \\
\text { note regarding allergy } \\
\text { information change. }\end{array}$ \\
\hline
\end{tabular}


Table 1 (continued)

\begin{tabular}{lll}
\hline Error type & Description & Exclusion \\
\hline $\begin{array}{l}\text { Sociotechnical } \\
\text { (post-HEP- }\end{array}$ & $\begin{array}{l}\text { Error caused by HEPMA } \\
\text { system, e.g. } \\
\text { MA) }\end{array}$ & $\begin{array}{l}\text { Error unlikely to be caused } \\
\text { by HEPMA. }\end{array}$ \\
& $\begin{array}{l}\text { tablets instead of plain } \\
\text { tablets. }\end{array}$ & \\
\hline
\end{tabular}

\section{Potential harm}

The panel met and discussed each error in turn, assigning a severity score. If consensus was not achieved, the error was referred to an independent medical consultant for further assessment.

\section{Data analysis}

Data were input to Statistical Packages for Social Sciences (SPSS) version 21.0, and analysed using descriptive statistics, normality tests and inferential statistics [22]. The ShapiroWilk normality test was applied to determine data distribution; Mann Whitney $U$ test was used for non-parametric variables including patient length of stay and discharge specialty. Categorical variables were analysed using chi-square test for data with values greater than zero and Fisher exact test for data including a count of zero. The accepted level for significance was $p<0.05$.

\section{Governance}

The study was approved by the ethical review panel of a UK university; NHS ethics was not required as it was considered a 'service evaluation'. Caldicott guardian approval was obtained to access patient confidential information [23].

\section{Results}

Data were found to follow a non-parametric distribution. There were statistically significant differences between groups as depicted in Table $2(p>0.05)$. The median age was 60 years pre-implementation and 59 post-implementation, with gender consistent at $57 \%$ female. The most common length of stay was 2 days for both groups and discharge specialty was consistent with $47 \%$ medical specialties; more medicines were prescribed post-implementation ( $p=0.023$ ). There was a statistically significant improvement in some aspects of documentation (patient's GP details, allergy information, grades of staff); no impact on others (hospital consultant, relevant secondary diagnosis, signature and full name printed); while certain sections were associated with reduced information documentation (diagnosis and procedures/operations) (Table 3).

Table 4 gives the comparison of prescribing errors pre- and post-HEPMA implementation. There was a statistically significant reduction in the number of patients with a prescribing error post-HEPMA implementation, a reduction from $158(99.4 \%)$ to $37(23.3 \%)$ patients $(p<0.001$.). The prevalence of all error types was reduced, being statistically significant for omitted medicines, medicine commission, incorrect doses, incorrect frequencies, incorrect durations and missing allergies (Table 4). Sociotechnical errors were attributed to prescriber selection failure for formulations and administration route for eye drops. Multiple error types were detected in $41.5 \%(n=66)$ preimplementation patients reduced to $2 \%(n=3)$ post-implementation. Multiple instances of the same error (for example, omitted medicines) occurred in 56\% $(n=89)$ pre-implementation patients reduced to $7 \%(n=11)$ post-implementation.

\section{Error severity scoring}

Errors were detected in $23 \%$ of post-implementation patients $(n=37)$. Severity scoring results gave category 1 errors
Table 2 Comparison of pre- and post-implementation results

\begin{tabular}{|c|c|c|c|}
\hline Variable & $\begin{array}{l}\text { Pre-implementation } \\
(n=159)\end{array}$ & $\begin{array}{l}\text { Post-implementation } \\
(n=159)\end{array}$ & $\begin{array}{l}\text { Significance } p \\
\text { value }\end{array}$ \\
\hline Age range (years) & 18-102 & $17-93$ & 0.416 \\
\hline Gender & $\begin{array}{l}\text { Median } 60 \\
57 \% \text { female }\end{array}$ & $\begin{array}{l}\text { Median } 59 \\
57 \% \text { female }\end{array}$ & \\
\hline Length of stay (days) & $1-25$ & $1-33$ & 0.232 \\
\hline Discharge specialty & $\begin{array}{l}\text { Mode } 2 \\
\text { Medical } 47 \%\end{array}$ & $\begin{array}{l}\text { Mode } 2 \\
\text { Medical 47\% }\end{array}$ & 0.688 \\
\hline & Surgical $33 \%$ & Surgical $30 \%$ & \\
\hline $\begin{array}{l}\text { Range of number of discharge } \\
\text { medicines }\end{array}$ & $\begin{array}{l}0-25 \\
\text { Median } 5.0\end{array}$ & $\begin{array}{l}0-18 \\
\text { Median } 6.0\end{array}$ & 0.023 \\
\hline $\begin{array}{l}\text { Total number of IDL prescribed } \\
\text { medicines }\end{array}$ & 872 & 1018 & 0.023 \\
\hline
\end{tabular}


Table 3 Comparison of documented information on IDL

\begin{tabular}{|c|c|c|c|c|}
\hline $\begin{array}{l}\text { Comparison of number and percentage of } \\
\text { patients with required information }\end{array}$ & $\begin{array}{l}\text { Pre-HEPMA } \\
n=159 \mathrm{~N}(\%)\end{array}$ & $\begin{array}{l}\text { Post-HEPMA } \\
n=159 \mathrm{~N}(\%)\end{array}$ & $\begin{array}{l}\text { Chi- } \\
\text { square }\end{array}$ & $p$ value \\
\hline Patient's GP details & $89(56.0)$ & $157(98.7)$ & 83.019 & $<0.001$ \\
\hline Hospital consultant & $154(96.9)$ & $159(100)$ & $\begin{array}{c}\text { Fisher } \\
\text { ex- } \\
\text { act* }\end{array}$ & 0.0605 \\
\hline Diagnosis & $153(96.2)$ & $116(73.0)$ & 33.028 & $<0.001$ \\
\hline Relevant secondary diagnosis & $48(30.2)$ & $49(30.8)$ & 0.015 & 0.902 \\
\hline Procedures/operations & $99(62.3)$ & $62(39.0)$ & 17.223 & $<0.001$ \\
\hline Allergy information & $11(6.9)$ & $159(100)$ & $\begin{array}{l}\text { Fisher } \\
\text { exact }\end{array}$ & $<0.0001$ \\
\hline Signature & $159(100)$ & $159(100)$ & $\begin{array}{l}\text { Fisher } \\
\text { exact }\end{array}$ & 1.0 \\
\hline Full name printed & $157(98.7)$ & $159(100)$ & $\begin{array}{l}\text { Fisher } \\
\text { exact }\end{array}$ & 0.4984 \\
\hline Grade of staff & $64(40.2)$ & $159(100)$ & $\begin{array}{l}\text { Fisher } \\
\text { exact }\end{array}$ & $<0.0001$ \\
\hline
\end{tabular}

(causing no potential harm) in $8(22 \%)$ of patients with errors, category 2 errors (monitoring or intervention potentially required to preclude harm) in $19(53 \%)$ and category 3 errors (likely to cause potential patient harm) in only 8 (22\%). Table 5 provides example error descriptions with associated score. Severity score 1 errors included incorrect formulation selected and 5 days of cyclizine supplied on discharge when none had been administered during the inpatient stay.

Assessors agreed for all severity scoring.

The null hypothesis was rejected; HEPMA implementation positively impacted discharge letter quality, with a reduction in prescribing error frequency and severity of errors.

Table 4 Comparison of prescribing errors

\begin{tabular}{|c|c|c|c|c|}
\hline $\begin{array}{l}\text { Comparison of number and } \\
\text { percentage of patients with } \\
\text { prescribing errors }\end{array}$ & $\begin{array}{l}\text { Pre- } \\
\text { HEPMA } \\
n=159 \mathrm{~N} \\
(\%)\end{array}$ & $\begin{array}{l}\text { Post- } \\
\text { HEPMA } \\
n=159 \mathrm{~N} \\
(\%)\end{array}$ & $\begin{array}{l}\text { Chi- } \\
\text { square }\end{array}$ & $\begin{array}{l}p \\
\text { value }\end{array}$ \\
\hline $\begin{array}{l}\text { Patients with errors } \\
\text { including omitted allergy } \\
\text { information }\end{array}$ & $158(99.4)$ & $37(23.3)$ & 194.115 & $<0.001$ \\
\hline $\begin{array}{l}\text { Patients with errors } \\
\text { excluding NKDA }\end{array}$ & $134(84.3)$ & $37(23.3)$ & 119.03 & $<0.001$ \\
\hline Omitted medicines & $66(41.5)$ & $18(11.3)$ & 37.275 & $<0.001$ \\
\hline Medicine commissions & $10(6.3)$ & $1(0.6)$ & 7.627 & 0.006 \\
\hline Incorrect doses & $14(8.8)$ & $1(0.6)$ & 11.824 & $<0.001$ \\
\hline Incorrect frequencies & $30(18.9)$ & $2(1.3)$ & 27.241 & $<0.001$ \\
\hline Incorrect durations & $43(27.0)$ & $3(1.9)$ & 40.665 & $<0.001$ \\
\hline Drug interactions & $7(4.4)$ & $1(0.6)$ & 4.616 & 0.032 \\
\hline Therapeutic duplications & $5(3.1)$ & $4(2.5)$ & 0.114 & 0.736 \\
\hline Missing allergies & $154(96.9)$ & $2(1.3)$ & 290.72 & $<0.001$ \\
\hline Incorrect allergies & $2(1.3)$ & 0 & $\begin{array}{l}\text { Fisher } \\
\text { exact }\end{array}$ & 0.498 \\
\hline Sociotechnical error & 0 & $8(5.0)$ & $\begin{array}{l}\text { Fisher } \\
\text { exact }\end{array}$ & 0.007 \\
\hline
\end{tabular}

$1=$ no potential harm, $2=$ monitoring or intervention potentially required to preclude harm, $3=$ potential harm

\section{Discussion}

\section{Key findings}

The key study findings relate to discharge letter quality and the nature and type of prescribing errors. HEPMA implementation resulted in an improvement in information content and accuracy. An improvement for almost all assessed SIGN guideline criteria was a consequence of HEPMA implementation [13]. HEPMA implementation significantly reduced the number of patients with prescribing errors $(p<0.001)$. Allergy information documentation improved with missing allergy information practically eliminated $(p<0.0001)$. Medicine omission was the most frequent error type post-implementation, although the incidence was significantly reduced compared to pre-implementation levels $(p<0.001)$. Errors related to the system (sociotechnical errors) were detected in 5\% postimplementation patients $(n=8)$. HEPMA prescribing errors were categorised as potentially associated with harm in $5 \%$ patients $(n=8)$.

\section{Strengths and weaknesses}

The study strengths include application of a consistent approach by use of an adapted validated tool and appropriate study design to minimise bias wherever possible. Biases minimised were measurement bias by use of a validated tool and non-response and sampling biases by use of a random patient sample and by systematic application of the sample. There are, however, 
Table 5 Post-HEPMA error severity scoring examples

\begin{tabular}{|c|c|c|}
\hline Error description & Error type & $\begin{array}{l}\text { Severity } \\
\text { score }\end{array}$ \\
\hline $\begin{array}{l}\text { Co-prescribed fluoxetine and amitriptyline (only taking amitriptyline prior to } \\
\text { admission) }\end{array}$ & $\begin{array}{l}\text { Therapeutic } \\
\text { duplication }\end{array}$ & 2 \\
\hline $\begin{array}{l}\text { No medicines added to IDL but patient had } 18 \text { medicines prescribed and } \\
\text { administered as inpatient which should be continued on discharge. }\end{array}$ & Omission & 3 \\
\hline Esomeprazole $40 \mathrm{mg}$ once daily prescribed as inpatient but omitted from IDL. & Omission & 2 \\
\hline $\begin{array}{l}\text { Wrong formulation of phenoxymethylpenicillin selected; syrup instead of } \\
\text { tablets. }\end{array}$ & Sociotechnical & 1 \\
\hline $\begin{array}{l}\text { Lantus }{ }^{\circledR} \text { and Humulin } \mathrm{S} \circledast \text { on IDL with no frequency documented. Marked as } \\
\text { charted but the insulin chart would not be sent to the patient's GP. }\end{array}$ & $\begin{array}{l}\text { Incorrect } \\
\text { frequency }\end{array}$ & 1 \\
\hline $\begin{array}{l}\text { Simvastatin withheld during inpatient stay as co-prescribed clarithromycin. } \\
\text { Information documented on IDL to restart simvastatin once antibiotics } \\
\text { completed. Simvastatin and clarithromycin both prescribed on IDL and both } \\
\text { dispensed. }\end{array}$ & Drug interaction & 2 \\
\hline $\begin{array}{l}\text { 5-day supply of cyclizine requested on IDL but not administered during } \\
\text { inpatient stay. }\end{array}$ & Commission & 1 \\
\hline $\begin{array}{l}\text { Clomipramine prescribed in morning but should be at night as per admission } \\
\text { medicine reconciliation. (HEPMA defaults to } 10 \mathrm{p} . \mathrm{m} \text {. time). }\end{array}$ & $\begin{array}{l}\text { Incorrect } \\
\text { frequency }\end{array}$ & 2 \\
\hline $\begin{array}{l}\text { Amiodarone } 200 \mathrm{mg} \text { tablets selected for } 100 \mathrm{mg} \text { dose (100 mg tablets } \\
\text { available). }\end{array}$ & Sociotechnical & 2 \\
\hline $\begin{array}{l}\text { Commenced on zopiclone for night sedation but developed a skin rash so } \\
\text { stopped. Information not documented on IDL nor allergy status updated. }\end{array}$ & Omitted allergy & 3 \\
\hline $\begin{array}{l}\text { Palliative care recommended codeine and sevredol for pain as tramadol no } \\
\text { longer effective but all three on IDL plus dihydrocodeine. }\end{array}$ & $\begin{array}{l}\text { Therapeutic } \\
\text { duplication }\end{array}$ & 3 \\
\hline $\begin{array}{l}\text { Meloxicam, azathioprine and sulfasalazine should be restarted at normal doses } \\
\text { 1-week post-discharge but none prescribed on IDL and not mentioned on } \\
\text { IDL. }\end{array}$ & Omission & 3 \\
\hline $\begin{array}{l}\text { Tranexamic acid should be continued until clinic appointment but marked as } \\
\text { 28-day supply with GP to continue. }\end{array}$ & $\begin{array}{l}\text { Incorrect } \\
\text { duration }\end{array}$ & 2 \\
\hline $\begin{array}{l}\text { Omeprazole prescribed as gastrointestinal cover while on diclofenac but } \\
\text { information not communicated to GP so potential could be continued. }\end{array}$ & $\begin{array}{l}\text { Incorrect } \\
\text { duration }\end{array}$ & 3 \\
\hline $\begin{array}{l}\text { Allergy information recorded as other (see medical notes). There was an } \\
\text { inpatient note documented as sodium benzoate causes mouth ulcers but note } \\
\text { not added to the IDL. }\end{array}$ & Missing allergy & 2 \\
\hline
\end{tabular}

several limitations hence the study findings should be interpreted with caution. While a randomised control trial would be the ideal study design, this was not possible due to the nature of HEPMA implementation within the study setting. Other limitations were the before and after design which resulted in different patients in the two phases. Severity scoring assessment is noted to be subjective and the panel was limited to the perspectives of one medical consultant and one senior pharmacist. There may have been other confounders between the two study periods impacting the findings. These included changes in medical staff and other changes in operational processes. Furthermore, there was no consideration of actual patient harm as a result of prescribing errors.

\section{Interpretation}

This study demonstrated improvements to discharge information content and accuracy while previous studies had reported inconsistent results when moving to electronic systems, although disparate methods were employed in the different studies [17, 24-26]. The documentation of diagnosis in the designated section of the IDL was reduced although frequently, this information was incorporated into the clinical progress section. A similar finding was reported by Callen et al. when they compared electronically produced letters to handwritten ones [24]. Prescribing error frequency was reduced as a consequence of HEPMA implementation. HEPMA confers automatic import of information from the inpatient chart to the IDL which is consistent with a recommendation by Kriplalani et al. that 'hospitals should use information technology to extract information into discharge summaries to ensure accuracy (e.g. medication names and doses) and to facilitate rapid completion of summaries' [27]. HEPMA implementation eradicates medicine transcription for IDLs which was predicted to reduce prescribing errors and increase the total number of medicines prescribed on IDLs [17, 24]. Grimes et al. in an observational study reported medicine discrepancies in $66 \%$ patients at hospital discharge [28]. HEPMA 
implementation reduced prescribing errors from 84 to $23 \%$ patients (excluding omitted allergy information). The most frequent post-implementation prescribing error type was omitted medicines, as demonstrated in retrospective studies focusing on electronic discharge systems [17, 24, 28-30]. Sociotechnical errors accounted for 10 (13\%) of postimplementation errors and therefore the HEPMA system prevented more errors than it created. This is consistent with inpatient electronic prescribing error occurrence detected by incident report review [6]. Errors occurring as a consequence of making changes to inpatient charts after preparation of IDLs have been reported when transcribing information from paper inpatient to electronic discharge letters [24]. A similar error was detected post-HEPMA, despite a system alert to indicate that the IDL also required to be changed. Thus, HEPMA implementation has not completely eliminated prescribing errors. The majority of detected prescribing errors were classified as execution errors in Reason's model (slips or lapses) which generally occur due to human fallibility [20]. Hence, evidence of planning failures remained where practitioners considered their erroneous actions to be correct.

Comparison with published studies indicates that error severity is lower with HEPMA compared to traditional handwritten processes. Published error severity varied and a range of severity scoring assessments were utilised. Grimes et al. reported error severity rates in handwritten IDLs as $47 \%$ no harm or minor potential harm, with $53 \%$ as moderate potential patient harm [28]. McMillan et al. assessed $88 \%$ of errors as minor or potentially troublesome for handwritten discharge letters [31]. Abdel-Qader et al. categorised discharge electronic prescribing errors as serious $2.9 \%$, significant $76.3 \%$ and minor $20.8 \%$ [30].

\section{Conclusion}

This study has provided evidence that HEPMA implementation in a UK DGH hospital was associated with a statistically significant reduction in discharge prescribing errors and severity of prescribing errors with a concurrent improvement in discharge information content. The electronic system is not a panacea for prescribing errors as system-related errors were detected although with a lower error severity than pre-existing error types.

Acknowledgements This work was supported in part by NHS Education for Scotland who provided partial funding for a Doctorate of Professional Practice. We are grateful to the health records staff for their invaluable assistance in obtaining case notes and to Lynsay Lawless and Sarah McDonald for ensuring accuracy of data extraction.

Contributions of authors statement PM conceived idea. PM, DS and AW were all involved in study design. PM completed review of patients' clinical notes, data analysis, data interpretation and drafted manuscript.
DS and AW assisted with data analysis and interpretation and critically reviewed the manuscript for intellectual content.

\section{Compliance with ethical standards}

Conflict of interest The authors declare they have no conflicts of interest.

Open Access This article is distributed under the terms of the Creative Commons Attribution 4.0 International License (http:// creativecommons.org/licenses/by/4.0/), which permits unrestricted use, distribution, and reproduction in any medium, provided you give appropriate credit to the original author(s) and the source, provide a link to the Creative Commons license, and indicate if changes were made.

\section{References}

1. Department of Health. (2007) NHS Connecting for Health. ePrescribing Baseline Functional Specifications for NHS Trusts. Available from http://webarchive.nationalarchives.gov.uk/ 20130502102046/http://www.connectingforhealth.nhs.uk/ systemsandservices/eprescribing/baselinefunctspec.pdf Date accessed 06/03/16

2. Department of Health. (2013) $£ 260$ million invested in patient safety plan. Available from https:///www.gov.uk/government/news/260million-invested-in-patient-safety-plans Date accessed 06/03/2016

3. The Scottish Government. eHealth Strategy 2011-2017 (Revised July 2012 to include a Sixth Strategic Aim). (2012) Available from http://www.scotland.gov.uk/Publications/2012/11/7663/0 Date accessed 06/03/2016

4. The Health Foundation. (2012) Evidence Scan: Reducing prescribing errors. Available from http://www.health.org.uk/publications/ reducing-prescribing-errors/ Date accessed 06/03/2016

5. Cornford T, Franklin BD, Savage I, Barber N, Yani, J (2009) Electronic prescribing in hospitals-challenges and lessons learned. Report Commissioned by NHS (National Health Service), London, UK: Connecting for Health

6. Redwood S, Rajakumar A, Hodson J, Coleman JJ (2011) Does the implementation of an electronic prescribing system create unintended medication errors? A study of the sociotechnical context through the analysis of reported medication incidents. BMC Med Inform Decis Mak 11(1):29-39

7. Ahmed Z, McLeod MC, Barber N, Jacklin A, Franklin BD (2013) The use and functionality of electronic prescribing systems in English Acute NHS Trusts: a cross-sectional survey. PLoS One 8(11):e80378. doi:10.1371/journal.pone.0080378

8. Donyai P, O'Grady K, Jacklin A, Barber N, Franklin BD (2008) The effects of electronic prescribing on the quality of prescribing. Br J Clin Pharmacol 65(2):230-237

9. Dornan T, Ashcroft D, Heathfield H, Lewis P, Miles J, Taylor D, Tully M, Wass V. (2009) An in depth investigation into causes of prescribing errors by foundation trainees in relation to their medical education. EQUIP study. Available from http://www.gmc-uk.org/ FINAL Report prevalence and causes of prescribing errors. pdf 28935150.pdf. Date accessed 06/03/2016

10. Mills PR, Weidmann AE, Stewart D (2016) Hospital discharge information communication and prescribing errors: a narrative literature overview. Eur J Hosp Pharm 23:3-10

11. Healthcare Improvement Scotland (2014) Implementing an electronic prescribing and medicines administration system: a good practice guide. Available from http:/healthcareimprovementscotland.org/his/ 
idoc.ashx\%3Fdocid\%3 D 0417 f48f-a066-42b8-b9ec92c9a386e5a7\%26version\%3D-1\&rct=j\&frm $=1 \& \mathrm{q}=\&$ esrc $=\mathrm{s} \& \mathrm{sa}=$ U\&ved=0ahUKEwiOpeS13q7LAhUCkA8KHTKBBKAQF ggUMAA\&usg=AFQjCNEJuKPEy6A9OvhZ2sr8iPSuMzUZEQ Date accessed 06/03/17. NHS Scotland

12. Picton C, Wright H (2012) Keeping patients safe when they transfer between care providers- getting the medicine right final report. Royal Pharmaceutical Society, London

13. Scottish Intercollegiate Guidelines Network (SIGN). (2012) 128 The SIGN Discharge Document. Available from www.sign.ac.uk Date accessed 14/08/16.

14. NHS England (2014) Patient safety alert stage one: warning risks arising from breakdown and failure to act on communication during handover at the time of discharge from secondary care. Available from http://www.england.Nhs.uk/2014/08/29/psa-communication/ Date accessed 06/03/17

15. O'Riordan C, Delaney T, Grimes T (2016) Exploring discharge prescribing errors and their propagation post-discharge: an observational study. Int J Clin Pharm 38:1172-1181

16. Armor BL, Wight AJ, Carter SM (2016) Evaluation of adverse drug events and medication discrepancies in transitions of care between hospital discharge and primary care follow-up. J Pharm Pract 29(2): 132-137

17. Callen JL, Alderton M, McIntosh J (2008) Evaluation of electronic discharge summaries: a comparison of documentation in electronic and handwritten discharge summaries. Int J Med Inform 277(9): 613-620

18. Dean B, Barber N, Schachter M (2000) What is a prescribing error? Qual Health Care 9(4):232-237

19. Westbrook JI, Baysari MT, Li L, Burke R, Richardson KL, O Day R. (2013) The safety of electronic prescribing: manifestations, mechanisms, and rates of system-related errors associated with two commercial systems in hospitals. J Am Med Inform Assoc 20(6):1159-1167

20. Reason J (2000) Human error: models and management. BMJ 320(7237):768-770
21. Gleason KM, McDaniel MR, Feinglass J, Baker DW, Lindquist L, Liss D, Naskin GA (2010) Results of the medications at transitions and clinical handoffs (MATCH) study: an analysis of medication reconciliation errors and risk factors at hospital admission. J Gen Intern Med 25(5):441-447

22. IBM (2013) SPSS software version 21. Available from http://www01.ibm.com/software/uk/analytics/spss/ Date accessed 06/13/17

23. Caldicott $F$ (2013) Information: to share or not to share. Information governance review. Department of Health, London

24. Callen J, McIntosh J, Li J (2010) Accuracy of medication documentation in hospital discharge summaries: a retrospective analysis of medication transcription errors in manual and electronic discharge summaries. Int J Med Inform 79:58-64

25. Scullard P, Iqbal N, White L, Olla E, Thomson GA (2007) Improved communication between hospital and general practice using online patient discharge summaries. J Telemed Telecare 13:56-58

26. Hammad EA, Wright DJ, Walton C, Nunney I, Bhattacharya D (2014) Adherence to UK national guidance for discharge information: an audit in primary care. Br J Clin Pharmacol 78(6):14531464

27. Kripalani S, LeFevre F, Phillips CO, Williams MV, Basaviah P, Baker DW (2007) Deficits in communication and information transfer between hospital-based and primary care physicians: implications for patient safety and continuity of care. Jama 297:831-841

28. Grimes T, Delaney T, Duggan C, Kelly JG, Graham IM (2008) Survey of medication documentation at hospital discharge: implications for patient safety and continuity of care. Ir J Med Sci 177(2): 93-97

29. Witherington EMA, Pirzada OM, Avery AJ (2008) Communication gaps and readmissions to hospital for patients aged 75 years and older: observational study. Qual Saf Health Care 17(1):71-75

30. Abdel-Qader DH, Harper L, Cantrill JA, Tully MP (2010) Pharmacists' interventions in prescribing errors at hospital discharge. Drug Saf 33(11):1027-1044

31. McMillan TE, Allan W, Black PN (2006) Accuracy of information on medicines in hospital discharge summaries. Intern Med J 36(4): 221-225 